\title{
ELASTIC-PLASTIC AND RESIDUAL STRESSES IN CLAMPED THERMOPLASTIC COMPOSITE LAMINATES LOADED TRANSVERSELY
}

\author{
Semih Benli ${ }^{1}$, Mustafa Karamolla ${ }^{2}$, Fuat Okumus ${ }^{3}$ and Onur Sayman ${ }^{4 *}$ \\ ${ }^{1}$ Aksaray University, Faculty of Engineering, Mechanical Engineering, Aksaray \\ ${ }^{2}$ Celal Bayar University, Faculty of Engineering, Mechanical Engineering, Manisa \\ ${ }^{3}$ Gediz University, Faculty of Engineering, Mechanical Engineering, Izmir \\ ${ }^{4}$ University of TOBB, Faculty of Engineering, Mechanical Engineering, Ankara \\ E-mail address: onur.sayman@deu.edu.tr
}

\begin{abstract}
In this study, an elastic-plastic stress analysis was carried out in woven steel fibers- thermoplastic clamped composite laminates. The stacking sequences were chosen as $[0 / 0]_{2},[15 /-15]_{2},[30 /-30]_{2}$ and $[45 /-45]_{2}$ for woven steel fibers thermoplastic composites plates. The layers were chosen for symmetric and antisymmetric cases.

The finite element solution was performed by using the ANSYS software. Solid 186 element was utilized in the solution. Normal stress components at the clamped edges were found to be higher than that at the mid point of the laminated plates. Normal stresses are tensile at the mid point of the clamped edges and compressive at the mid point of the laminated plates. Then, the residual stress components were calculated in the critical points of the composite laminates.
\end{abstract}

Keywords-elastic-plastic stress analysis, thermoplastic composite laminates, finite element method

\section{INTRODUCTION}

Thermoplastic composites gain some advantages in nowadays. Since its high impact resistance and reform again very easily, the use of the thermoplastic composites increases in the industry.

Ageorges et al. [1] presented a review in the advances in fusion bonding techniques for joining thermoplastic matrix composites. Trende et al. [2] investigated residual stresses and dimensional changes in the compression moulded glass-mat reinforced thermoplastic parts. Finite element calculations were used in the stress analysis. Ifo et al. [3] performed a micro mechanics analysis for tailoring glass-fiberreinforced thermoplastic laminates. Sayman [4] carried out an elasto-plastic stress analysis in aluminum metal matrix laminated plates loaded transversely by using finite element technique. The expansion of plastic region and residual stresses were determined. Jegley [5] presented a study of the effects of, impact damage on compression-loaded graphite thermoplastic sandwich panels. Some investigations were performed in metal-matrix composite laminates using finite element methods [6-9]. Shih and Loos [10] investigated heat transfer analysis of the thermoplastic filament winding process. They determined the temperature distribution in the composite during the fabrication process by using the ABAQUS transient heat transfer finite element model. Damb and Hansen [11] developed a numerical model for prediction of the process-induced thermal residual stresses in the thermoplastic composite laminates. The 
material was assumed to be strain-hardening. Parlevliet et al. [12] reviewed thermal residual stresses in thermoplastic composites arising at high temperatures. Özcan [13] performed elastic-plastic stress analysis in steel fiber reinforced thermoplastic composite laminated plates under in-plane loading. In this study, an elastic-plastic stress analysis was carried out in a steel fiber reinforced thermoplastic clamped plate using a finite element technique.

\section{MATERIALS AND METHODS}

\subsection{Experimental Study}

A low density polyethylene (LDFE, F.212) and woven steel fibers were used for manufacturing of the composite plate. Raw polyethylene granules were put into the steel moulds and then were heated up to $190{ }^{\circ} \mathrm{C}$ by using the electrical resistance. The raw material was held for 5 min under $0.5 \mathrm{MPa}$ pressure satisfied by an hydraulic press. Then, the temperature was decreased to $25{ }^{\circ} \mathrm{C}$ under $1.5 \mathrm{MPa}$ pressure in 3 minutes. Thus, a polyethylene layer was manufactured. A woven steel fiber substituted into the two thermoplastic layers for manufacturing a thermoplastic composite layer. The thickness of the composite layer was $2 \mathrm{~mm}$. Mechanical properties of the composite layer were measured by an INSTRON tensile machine. The moduli of the elasticity and poisson's ratio were measured by strain gauges. The shear modulus and the shear strength were found by using Arcan test apparatus. The plasticity constants of Ludwik equation such as $\mathrm{K}$ and $\mathrm{n}$ were measured in a tensile test as

$\sigma=\sigma_{o}+K \varepsilon_{p}^{n}$

where $\sigma_{o}$ can be assumed to be almost equal to $\sigma_{y}$ in the thermoplastic composite layers. The mechanical properties of the composite layer are given in Table 1.

Table 1. Mechanical properties of the thermoplastic composite layer

\begin{tabular}{|l|c|}
\hline Longitudinal modulus, $\mathrm{E}_{1}(\mathrm{MPa})$ & 2700 \\
\hline Transverse modulus, $\mathrm{E}_{2}(\mathrm{MPa})$ & 2700 \\
\hline Longitudinal tensile strength, $\mathrm{X}(\mathrm{MPa})$ & 26 \\
\hline Transverse tensile strength, $\mathrm{Y}(\mathrm{MPa})$ & 26 \\
\hline In-plane shear modulus, $\mathrm{G}_{12}(\mathrm{MPa})$ & 220 \\
\hline In-plane shear Strength, $\mathrm{S}_{12}(\mathrm{MPa})$ & 12.4 \\
\hline Poisson's ratio $\left(\mathrm{v}_{12}\right)$ & 0.14 \\
\hline Tangent Modulus, $\mathrm{K}(\mathrm{MPa})$ & 102 \\
\hline Hardening Parameter, $\mathrm{n}(\mathrm{MPa})$ & 0.615 \\
\hline
\end{tabular}

\subsection{Finite Element Solution}

The clamped plate loaded uniformly is shown in Fig 1. It consists of four layers and oriented as $\left[0^{\circ} / 0^{\circ}\right]_{2}, \quad\left[15^{\circ} /-15^{\circ}\right]_{2}, \quad\left[30^{\circ} \%-30^{\circ}\right]_{2}, \quad\left[45^{\circ} /-45^{\circ}\right]_{2}$. In this study, the solution was performed by using FEM solution. Solid layered 186 element was used in this solution [Figure 1 and 2.]. This element is convenient to the elastic-plastic solution. The solution was carried out under the linear hardens of the composite layer. 


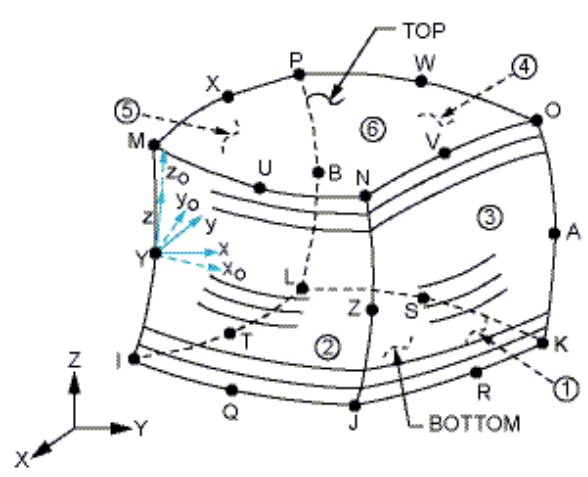

Figure 1. SOLID186 element

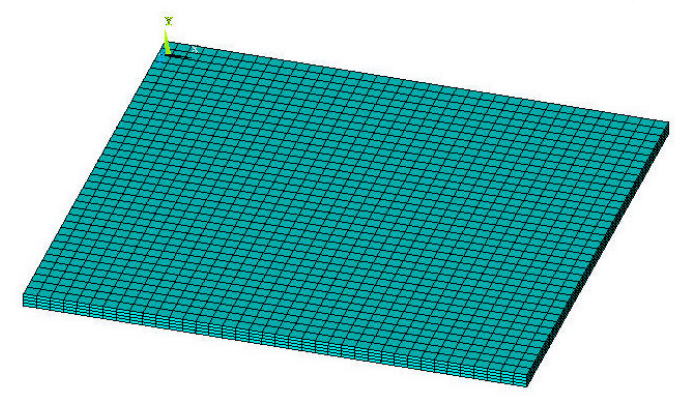

Figure 2. Finite element model of the composite plate

The points A, B, C, D, and E are chosen at the upper surface of the plate. A, B, $\mathrm{C}, \mathrm{D}$ are the mid points at the edges of the plate. $\mathrm{E}$ is the mid point at the center of the plate. They are the most critical points in the plate in a point of view of stress distribution. Boundary conditions are chosen to be equal to zero at the edges of the plate, for the clamped plates [Figure 3.].

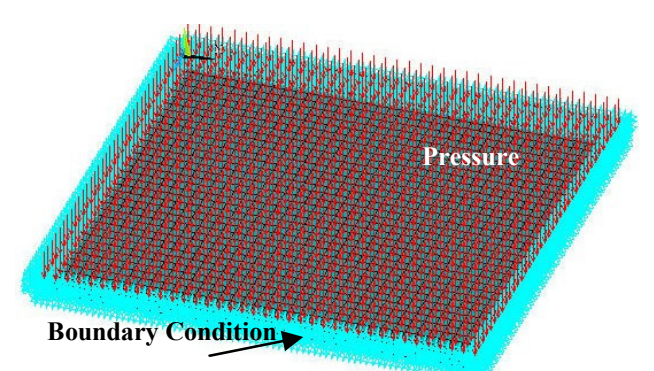

Figure 3. Loading and Boundary Conditions

The paths from point $\mathrm{A}$ to $\mathrm{B}$ and $\mathrm{C}$ to $\mathrm{D}$ were defined by selecting the nodes so that distributions of SX and SY stress components could be indicated in graphs. The paths are shown in Figure 4. 


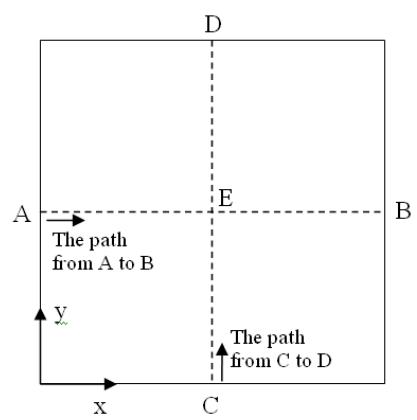

Figure 4. The most critical points and the paths defined to show stress distributions

\section{Results and Discussions}

The finite element solution was carried out in the plate. The yield point was obtained for each plate as shown in Table 2 .

Table 2. The yield point of the plates

\begin{tabular}{|c|c|c|}
\hline Orientation & p [MPa] for symmetric case & p [MPa] for antisymmetric case \\
\hline$\left[0^{\circ} / 0^{\circ}\right]_{2}$ & 0.088 & 0.088 \\
\hline$\left[15^{\circ} /-15^{\circ}\right]_{2}$ & 0.093 & 0.096 \\
\hline$\left[30^{\circ} /-30^{\circ}\right]_{2}$ & 0.124 & 0.131 \\
\hline$\left[45^{\circ} /-45^{\circ}\right]_{2}$ & 0.163 & 0.163 \\
\hline
\end{tabular}

It is seen that, the yield point of the plate is the highest for $\left[45^{\circ} /-45^{\circ}\right]_{2}$ orientations. It is the lowest for $\left[0^{\circ} / 0^{\circ}\right]_{2}$ orientations. The yield point of antisymmetric orientation is higher than that of the symmetric orientations. Stress components are the highest at A, B, C, D and E points. They are the mid points at the edges and mid point of the plate as $\mathrm{E}$ as shown in Fig 4. The pressure $\mathrm{p}$ is increased $0.5 \mathrm{MPa}$ from the yield point of the plates. Then, the solution is performed both elastic-plastic and elastic cases. The difference between the elastic-plastic and elastic stress components gives the residual stresses in each plate. The stress components for $[0 / 0]_{2}$ stacking sequences is given at the upper surface of the plate at Table 3.

Table 3. The stress components for the plate with $[0 / 0] 2$ stacking sequences

\begin{tabular}{|c|c|c|c|c|c|c|c|c|c|c|}
\hline & \multicolumn{4}{|c|}{ Elastic-plastic stresses [MPa] } & \multicolumn{5}{c|}{ Residual stresses [MPa] } \\
\hline Points & $\sigma_{x}$ & $\sigma_{z}$ & $\tau_{x z}$ & $\tau_{x y}$ & $\tau_{y z}$ & $\sigma_{x}$ & $\sigma_{z}$ & $\tau_{x z}$ & $\tau_{x y}$ & $\tau_{y z}$ \\
\hline A & 45.59 & 21.19 & 0.02 & -1.25 & 0.01 & -18.77 & 10.28 & 0.32 & 0.99 & -0.31 \\
\hline B & 21.15 & 45.60 & 0.04 & 0.05 & 1.13 & 10.78 & -18.16 & -0.21 & 0.08 & 2.04 \\
\hline C & 21.19 & 45.59 & 0.06 & 0.05 & -0.11 & 10.79 & -18.17 & 0.02 & -0.05 & 1.23 \\
\hline D & 45.59 & 21.19 & -0.02 & 0.01 & 1.25 & -18.77 & 10.78 & 0.02 & 0.05 & -0.01 \\
\hline E & -29.76 & -29.38 & -0.02 & 1.25 & 0.01 & 0.00 & 0.00 & 0.15 & -0.98 & -0.26 \\
\hline
\end{tabular}

As seen in this Table, the magnitudes of the residual stress components are the smallest at the mid point E. The residual stress components of the shear stresses are the smallest in comparison with the normal residual stresses. For symmetric stacking sequences, the distribution of SX stress component from point $\mathrm{C}$ to $\mathrm{D}$ is shown in Figures $5 \mathrm{a}$ and $5 \mathrm{~b}$, respectively while that of SY stress components from point $\mathrm{A}$ to $\mathrm{B}$ in Figures $5 \mathrm{c}$ and $5 \mathrm{~d}$. When elastic-plastic stress distributions are investigated, it is seen 
that SX elastic-plastic compressive stress decreases at the center point E while orientation angles are varied from $[0 / 0]_{\mathrm{s}}$ to $[45 /-45]_{\mathrm{s}}$. However, for the same variation of the orientation, SY elastic-plastic compressive stress increases. For [45/-45]s orientation, high SX compressive and SY tensile residual stresses occur at point $\mathrm{E}$ when compared to other orientations. At points A, B, C and D, the greatest SX residual stresses occur in the composite plate with $[0 / 0]_{\mathrm{S}}$ orientation. The SX and SY residual stresses at the clamped edges of the plates vary from tensile to compressive stress with changing of orientation angle from $[0 / 0]_{\mathrm{s}}$ to $[45 /-45]_{\mathrm{s}}$.

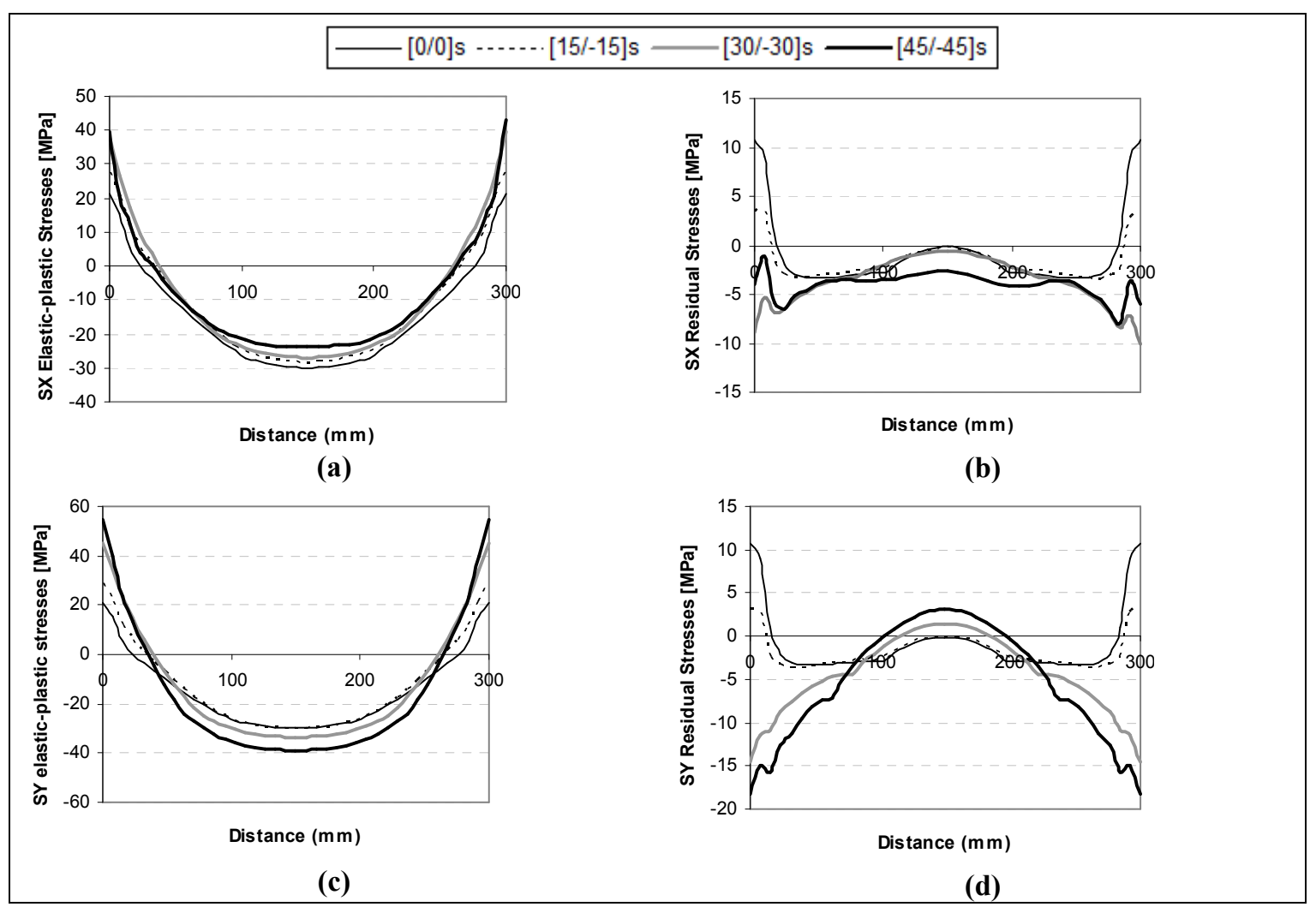

Figure 5. For symmetric orientations, distributions of SX and SY stress components

For antisymmetric laminates, the distributions of SX stress component from point $\mathrm{C}$ to $\mathrm{D}$ and that of SY from A to B are shown in Fig. 6 a-b and c-d, respectively. It is seen that both SX and SY elastic-plastic normal stresses are tensile at the clamped edges and compressive at the mid point of all the laminates. It is also seen the magnitudes of the normal stress components at the clamped edges are higher than those at the mid points of the plates. The residual stress components of SX and SY at the clamped edges are larger than that of SX and SY at the mid points. At the edges, both of them are tensile for $[0 / 0]_{\text {as }}$ and $[15 /-15]_{\text {as }}$ laminates while compressive for $[30 /-30]_{\text {as }}$ and $[45 /-45]_{\text {as }}$ stacking-sequences. 


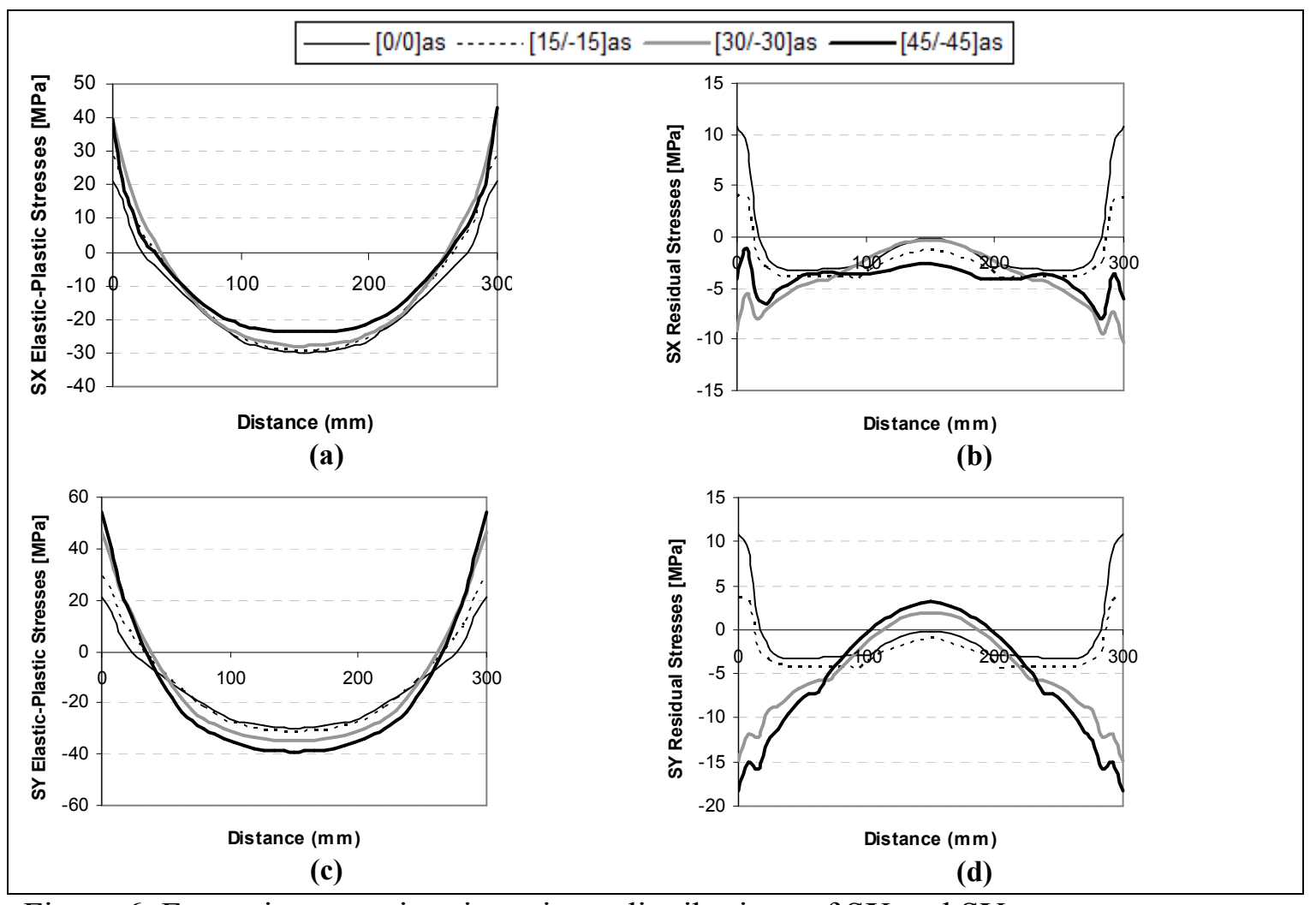

Figure 6. For antisymmetric orientations, distributions of SX and SY stress components

At the edges of the plates, the shear residual stresses are greater in comparison with other regions of the plate. At the center of the plates, the shear residual stresses are negligible. Also, for the only $[0 / 0]_{\mathrm{s}}$ orientation, Fig. 7 shows that the distributions of SXZ shear elastic-plastic and residual stress components from point $C$ to $D$ are the same as that of SYZ shear elastic-plastic and residual stress components from point A to B.

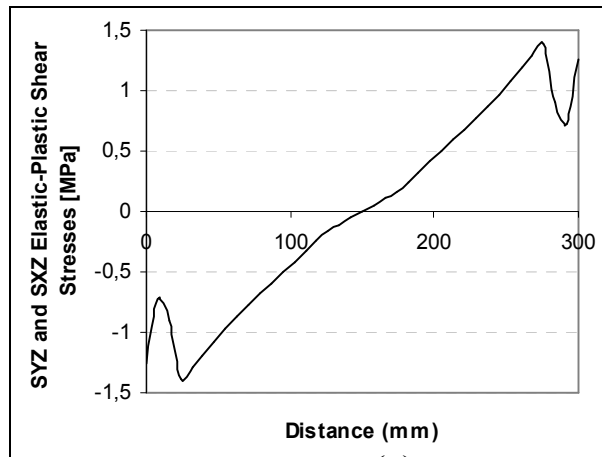

(a)

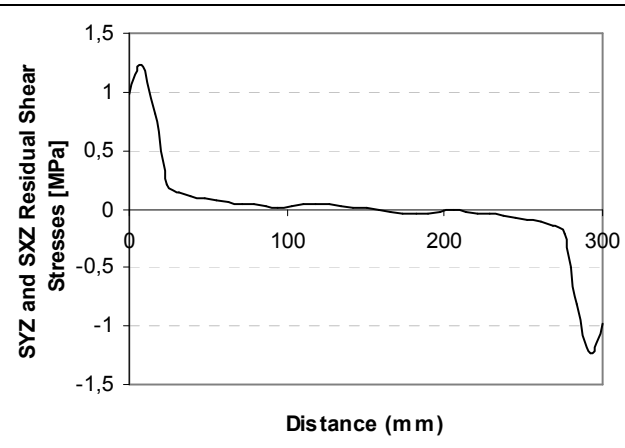

(b)

Figure 7. For the plates with $[0 / 0]_{\mathrm{s}}$ orientation, distributions of SYZ and SXZ shear stress components

For symmetric laminates, the distribution of SX stress component through the path from point $A$ to $B$ and that of SY from $C$ to D are shown in Fig. 8 a-b and c-d, respectively. At the points $\mathrm{A}, \mathrm{B}, \mathrm{C}$ and $\mathrm{D}$ of the clamped edges, the greatest 
compressive residual stresses occurs in $[0 / 0]_{\mathrm{S}}$ stacking sequences. Also, the SX and SY stress distributions through the paths from $\mathrm{A}$ to $\mathrm{B}$ and from $\mathrm{C}$ and $\mathrm{D}$ are identical for $[0 / 0]_{\mathrm{s}}$ laminate. The magnitudes of SY residual stress components at points $\mathrm{C}$ and $\mathrm{D}$ are nearly identical for $[0 / 0]_{\mathrm{s}}$ and $[45 /-45]_{\mathrm{s}}$ laminates.

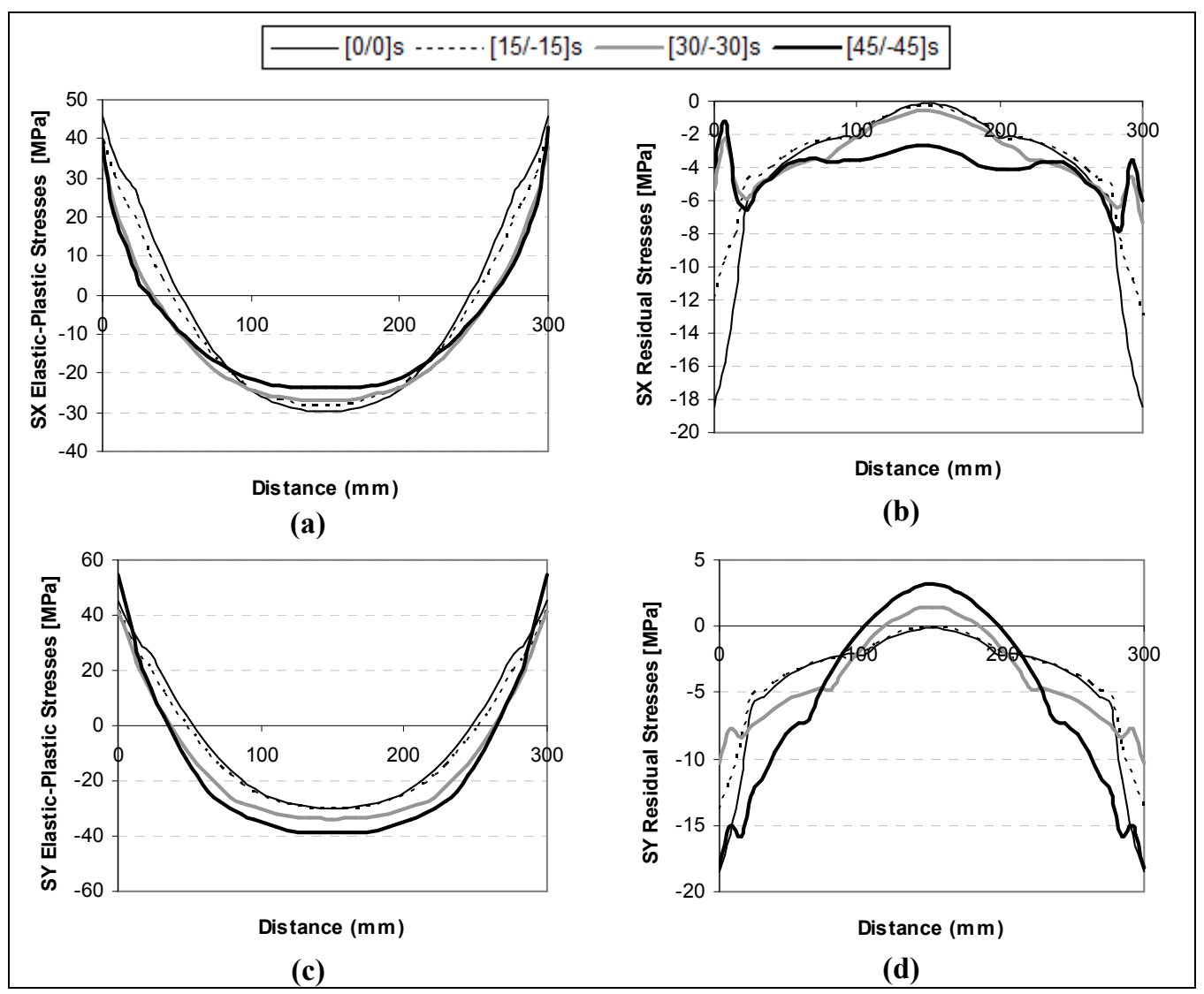

Figure 8. For symmetric laminates, the distribution of SX stress component through the path from point A to B and that of SY from C to D.

For antisymmetric laminates, the distribution of SX stress component through the path from point A to B and that of SY from C to D are shown in Fig. 9 a-b and c-d, respectively. It is seen from the figures that the stress distributions of antisymmetric laminates are nearly identical with that of symmetric laminates. 


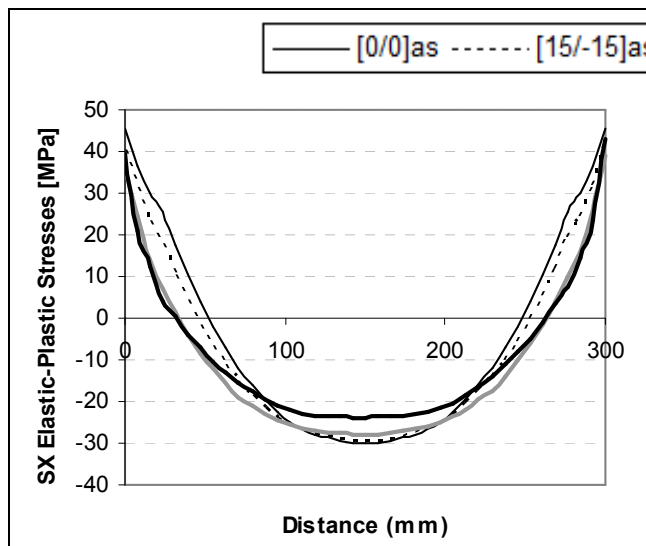

(a)

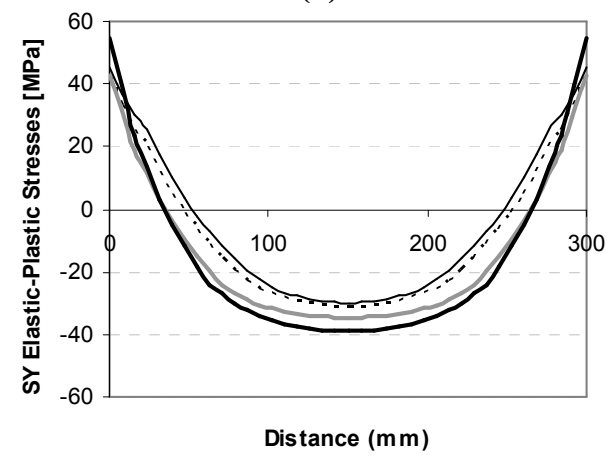

(c)

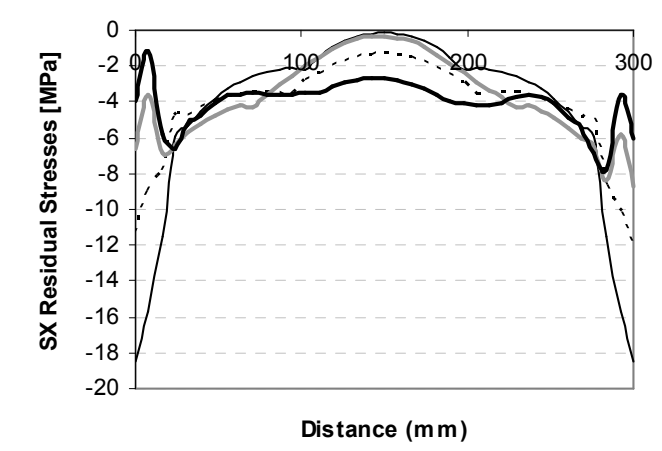

(b)

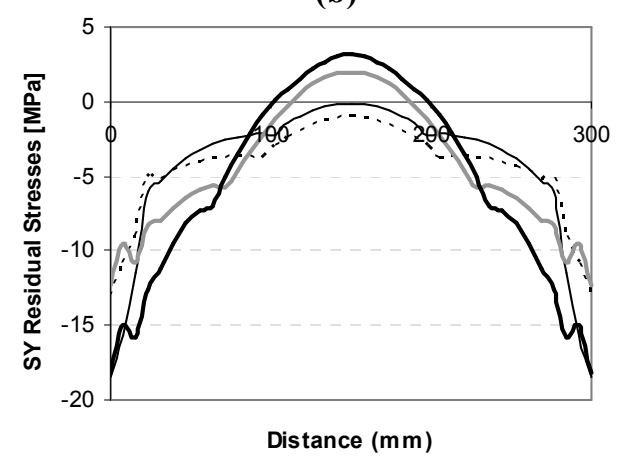

(d)

Figure 9. For antisymmetric laminates, the distribution of SX stress component through the path from point $\mathrm{A}$ to $\mathrm{B}$ and that of SY from $\mathrm{C}$ to $\mathrm{D}$.

Plots of SX elastic-plastic stress distributions in the plates with symmetric sequences are shown in Figure 10.

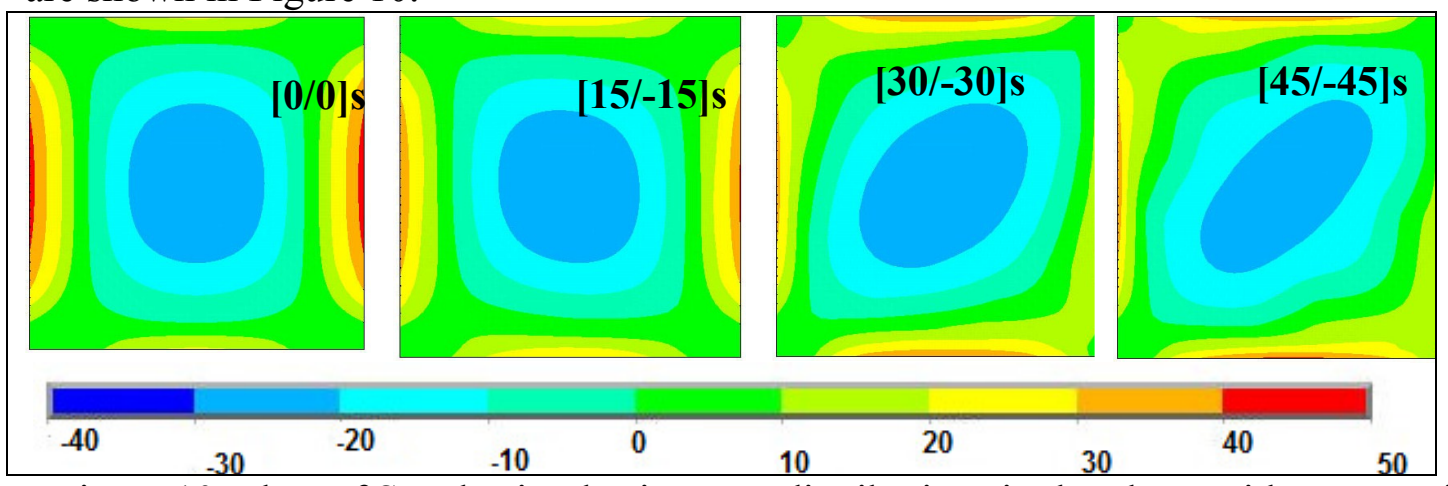

Figure 10. Plots of SX elastic-plastic stress distributions in the plates with symmetric orientation

\section{CONCLUSIONS}

In this study, elastic-plastic stress analyses of woven steel fibers - thermoplastic clamped composite laminates in $[0 / 0]_{2},[15 /-15]_{2},[30 /-30]_{2}$ and $[45 /-45]_{2}$ stacking sequences were carried out for both symmetric and antisymmetric cases. The analyses 
were performed using finite elements method in ANSYS software. The results can be summarized as follows:

The magnitudes of the residual stress components for each orientation are the smallest at the mid point of the composite plate. The residual stress components of the shear stresses are the smallest in comparison with the normal residual stresses.

The stress distributions of antisymmetric laminates are nearly identical with that of symmetric laminates.

Both SX and SY elastic-plastic normal stresses are tensile at the clamped edges and compressive at the mid point of all the laminates. It is also seen the magnitudes of the normal stress components at the clamped edges are higher than those at the mid points of the plates.

\section{REFERENCES}

1. Ageorges C. \& Ye Land Hou M., Advances in fusion bonding techniques for joining thermoplastic matrix composites: a review, Composites: Part A, 32, 2001, 839-857.

2. Trende A., Astrom B. T., Nilsson G., Modeling of residual stresses in compression moulded glass-mat reinforced thermoplastic, Composite Part A, 31, 200, 1241-1254

3. Ho T., Suganuma T. \& Wakashima K., A micromechanics- based analysis for tailoring glass-fiber-reinforced thermoplastic laminates with near-zero coefficients of thermal expansion, Composite Science and Technology, 60, 2000, 1851-1861.

4. Sayman O., Elasto-plastic stress analysis in stainless steel fiber reinforced aluminum methal matrix laminated plates loaded transversely, Composite Structures, 43, 1998, $147-154$

5. Jegley D., Impact-Damaged graphite-thermoplastic trapezoidal-corrugation sandwich and simi-sandwich panels, Journal of Composite Materials, 27, 1993, 526-538.

6. Sayman O. \& Aksoy S., Elastic-plastic stress analysis of simply supported and clamped aluminum metal-matrix laminated plates with a hole, Composite Structures, 53, 2001, 355-364.

7. Sayman O., Atas C., \& Callioglu H., Material nonlinear behavior of laminated metalmatrix composite plates supported at edges under uniform transverse loading, Composite Science and Technology, 62, 2002, 1913-1923.

8. Yildiz H., Sayman O., \& Aktas M., Effects of hardening exponent on residual stress and plastic zone growth in aluminum metal-matrix composites under out-of-plane loading, Journal of Reinforced Plastic and Composites, 23, 2004, 2065-2080.

9. Atas C., \& Sayman O., Elastic-plastic stress analysis and expansion of plastic zone in clamped and simply supported aluminum metal-matrix laminated plates, Composite Structures, 49, 2000, 9-19.

10. Shih P. J., \& Loos A. C., Heat Transfer analysis of the thermoplastic filament winding process, Journal of Reinforced Plastics and Composites, 18, 1999, 1103-1112.

11. Domb M. M., \& Hansen J. S., The effect of cooling rate on free-edge stress development in Semi-Crystallina thermoplastic laminates. Journal of Composite Materials, 32, 1998, 361-385.

12. Parlevliet P. P., Bersee H. E. N., \& Beukers A., Residual stresses in thermoplastic composites- A study of the literature-Part I; formation of residual stresses, Composites; Part A, 37, 2006, 1847-1857.

13. Ozcan R., Elastic plastic stress analysis in thermoplastic composite laminated plates under in plane loading, Composite Structures, 49, 2000, 201-208. 